\title{
Vimentin overexpression as a novel poor prognostic biomarker in eyelid sebaceous gland carcinoma
}

\author{
Mansi Bhardwaj, ${ }_{1}^{1}$ Seema Sen (1) , ${ }^{1}$ Kunzang Chosdol, ${ }^{2}$ Sameer Bakhshi, ${ }^{3}$ \\ Neelam Pushker 이, ${ }^{1}$ Anjana Sharma, ${ }^{4}$ Seema Kashyap, ${ }^{1}$ Mandeep S Bajaj, \\ Vijay Kumar Singh ${ }^{1}$
}

- Additional material is published online only. To view please visit the journal online (http://dx.doi.org/10.1136/ bjophthalmol-2018-313285).

'Department of Ocular Pathology, All India Institute of Medical Sciences, New Delhi, India

2Department of Biochemistry, All India Institute of Medical Sciences, New Delhi, India ${ }^{3}$ Department of Medical Oncology, IRCH, All India Institute of Medical Sciences, New Delhi, India

${ }^{4}$ Department of Ocular

Microbiology, All India Institute of Medical Sciences, New Delhi India

\section{Correspondence to} Dr Seema Sen, Ocular Pathology, Dr.R.P.Centre, All India Institute of Medical Sciences, New Delhi 110029 India; ssenop@rediffmail.com

Received 25 September 2018 Revised 16 February 2019 Accepted 9 March 2019 Published Online First 2 April 2019

\section{ABSTRACT}

Background Vimentin is an intermediate-sized filament which is highly expressed in mesenchymal cells and is associated with epithelial-mesenchymal transition (EMT). EMT markers ZEB2 and Slug lead to Vimentin overexpression and $\mathrm{E}$-cadherin loss, resulting in invasion and metastasis. However, the status of Vimentin remains unexplored in eyelid sebaceous gland carcinoma (SGC). The study aims to determine status of Vimentin in SGC and its association with EMT markers E-cadherin, ZEB2 and Slug.

Methods Vimentin protein expression was undertaken in 66 cases with SGC by immunohistochemistry (IHC). Messenger RNA (mRNA) expression was determined in 42 fresh tissues by quantitative real-time PCR. Association of Vimentin with E-cadherin, ZEB2 and Slug was also analysed. Patients were followed up for 17-69 months (mean $34.02 \pm 14.73$ months).

Results IHC revealed Vimentin overexpression in 37/66 $(56 \%)$ cases. This overexpression showed significant association with lymph node metastasis $(p=0.004)$ and pagetoid spread $(p=0.05)$. Patients with high Vimentin expression also had poor disease-free survival $(p=0.033)$. Univariate Cox regression model indicated that high Vimentin expression ( $p=0.043)$ and advanced tumour stage $(p=0.002)$ were independent adverse prognostic factors. High Vimentin mRNA expression was seen in $16 / 42(38 \%)$ cases and correlated significantly with lymph node metastasis ( $p=0.027)$, advanced tumour stage $(p=0.002)$ and large tumour size $(p=0.023)$. Vimentin expression overall showed a significant inverse association with E-cadherin and direct association with ZEB2 expression.

Conclusions Vimentin overexpression in SGC is associated with EMT and leads to poor clinical outcome. It also emerged as a novel predictor for lymph node metastasis and poor survival.

\section{INTRODUCTION}

Sebaceous gland carcinoma (SGC) of the eyelid is a highly malignant and potentially lethal cutaneous neoplasm which arises in the glands of Zeis associated with hair follicles and from meibomian glands. It accounts for $27 \%-44 \%$ of all eyelid malignancies in Asian population. ${ }^{12}$ However, it is less common in Caucasian regions accounting for only 1\%-5.5\% of all eyelid tumours. ${ }^{34}$ It is known as the 'great masquerader', as it is often misdiagnosed, leading to a delay in diagnosis which contributes to an increase in associated morbidity and mortality.
Epithelial-mesenchymal transition (EMT) is a critical phenomenon in invasion, progression and metastasis of epithelial malignancies, which is characterised by loss of epithelial morphology and acquisition of a highly invasive mesenchymal phenotype. ${ }^{5}$ Decrease in the expression of cell adhesion molecule E-cadherin and increased expression of mesenchymal markers such as Vimentin along with aberrant expression of transcription factors (like ZEB2 and Slug) are considered as hallmarks of EMT. ${ }^{5}$ Vimentin, a $57 \mathrm{kDa}$ protein, is an intermediate filament type III protein, that is expressed in normal mesenchymal cells to maintain cellular integrity and provide resistance against stress. It is expressed in a variety of cells including fibroblasts, endothelial cells, macrophages, neutrophils, leukocytes, etc. Overexpression of Vimentin in cancer correlates with tumour progression, metastasis and poor clinical outcome. It is overexpressed in various epithelial cancers including breast cancer, central nervous system (CNS) tumours, prostate cancer, malignant melanoma, lung cancer and gastrointestinal tumours. ${ }^{6}$ Transcription factors belonging to Snail family (Slug/Snail2) and ZEB family (ZEB2/ SIP1) are considered to be master regulators triggering EMT leading to transcriptional repression of E-cadherin gene. These transcriptional factors repress E-cadherin expression by targeting E-box element proximal to the E-cadherin promoter. ${ }^{7}$ Various reports on Slug and ZEB2 are available which have documented their ability to downregulate epithelial markers and upregulate mesenchymal markers leading to tumour invasion and metastasis in human breast, ${ }^{8}$ colorectal, ${ }^{9}$ esophageal, ${ }^{10}$ gastric, ${ }^{11}$ non-small-cell lung cancer, ${ }^{12}$ pancreatic ${ }^{13}$ and renal cell carcinoma. ${ }^{14}$

The present study aims to evaluate prognostic significance of Vimentin in eyelid SGC. In addition, its correlation with E-cadherin, ZEB2 and Slug expression was also undertaken.

\section{Materials and methods}

Patients and tissue samples

Paraffin blocks of 66 cases of histopathologically proven eyelid SGC were retrieved from the records of Department of Ocular Pathology, All India Institute of Medical Sciences (AIIMS), New Delhi, India between 2008 and 2015. Of these, 42 frozen tissue samples were collected from operation theatre of Dr. Rajendra Prasad Centre for Ophthalmic Sciences, AIIMS. Six adjoining normal epidermis resected about $10 \mathrm{~cm}$ from the main tumour served 
as controls. Frozen tissues were stored in RNA later solution overnight and then at $-80^{\circ} \mathrm{C}$ until further use. Only patients who had not received chemotherapy or radiotherapy prior to surgery were included in the study. The protocol of the study was approved by Institute's Ethical Committee, AIIMS (Ref. No. IEC/NP-250/03.07.2014) and conforms to the Declaration of Helsinki principles. Informed consent was obtained from all the patients enrolled in the study. Clinical and radiological details of all the patients were noted and they were followed up for 17-69 months (mean 34.02 \pm 14.73 months). The seventh edition of American Joint Committee on Cancer (AJCC) system (2009) was used to classify (primary) tumour, (regional) lymph node and (remote) metastasis (TNM) Stages. ${ }^{15}$ Haematoxylin and eosin-stained sections from formalin-fixed paraffin-embedded (FFPE) tumours were reviewed to determine the histological features of the tumour.

\section{Immunohistochemistry}

Expression pattern of EMT markers Vimentin, E-cadherin, ZEB2 and Slug was detected by immunohistochemistry (IHC). Briefly, unstained sections of 3-4 $\mu \mathrm{m}$ thick sections were cut on poly-L-lysine-coated slides from FFPE blocks and stained using avidin-biotin indirect method. Slides were deparaffinised and rehydrated followed by antigen retrieval in citrate buffer solution $(\mathrm{pH} 6.0)$ at $100^{\circ} \mathrm{C}$ for $20-30 \mathrm{~min}$. Thereafter, they were treated with $0.3 \%$ hydrogen peroxide in absolute methanol for $30 \mathrm{~min}$ to inactivate endogenous peroxidases. The slides were blocked with $1 \%$ bovine serum albumin for $30 \mathrm{~min}$ and were then incubated with rabbit monoclonal anti-human Vimentin antibody (Clone SP20; 1:50 dilution Abcam, Cambridge, UK), mouse monoclonal anti-human E-cadherin antibody (Clone HECD-1; 1:50 dilution; Abcam), rabbit polyclonal anti-human ZEB2 antibody (Clone AP01369PU-N; 1:400 dilution; Acris Antibodies GmbH, Herford, Germany) and rabbit monoclonal anti-human Slug antibody (Clone C19G7; 1:100 dilution; Cell Signalling Technology, Danvers, MA, USA). Subsequent incubations were performed using biotinylated secondary antibody and peroxidase-labelled streptavidin (LSAB +System HRP kit; Dako Cytomation, Glostrup, Denmark). Immunoreactivity was visualised using 3,3'-diaminobenzidine substrate for 3-4 min, counterstained with haematoxylin and visualised by light microscopy. Appropriate positive and negative controls were used in all the tests. For Vimentin immunoexpression, normal human tonsil was used as positive control. ${ }^{16}$ Breast carcinoma served as positive control for E-cadherin. ${ }^{17}$ Also, normal epidermis and normal sebaceous glands within the test samples served as internal positive controls for E-cadherin immunostaining. Highgrade glioma and hemangiopericytoma were used as positive controls for ZEB $2^{18}$ and Slug immunoexpression, respectively. ${ }^{19}$

\section{IHC scoring}

Expression of all the EMT markers was evaluated by examining the tissue sections light microscopically. Vimentin immunostaining was observed in stromal as well as tumour cells. Immunoexpression of Vimentin was considered positive when more than $10 \%$ tumour cells stained positive in 10 randomly selected high-power fields. ${ }^{20}$ The immunoreactivity scores for ZEB2 and E-cadherin expression were determined as described previously. ${ }^{21}$ Evaluation of Slug immunoexpression was based on percentage positivity. Positive expression was defined as detectable immunoexpression of Slug in perinuclear and/or other cytoplasmic regions of $>10 \%$ of the tumour cells in 10 randomly selected high-power fields. ${ }^{11}$

\section{RNA extraction and complementary DNA synthesis}

Total RNA from 42 fresh tumour tissues and six normal skin tissues (controls) were isolated using ReliaPrep ${ }^{\mathrm{TM}}$ RNA tissue miniprep system (Promega, WI, USA) according to the manufacturer's protocol. RNA concentration and purity were determined by optical density measurement using a nanodrop spectrophotometer (Thermo Scientific, Wilmington, DE, USA). Complimentary DNA was synthesised using $1 \mu \mathrm{g}$ of total RNA, random hexamers and Superscript ${ }^{\mathrm{TM}}$ III reverse transcriptase (Invitrogen) according to manufacturer's instructions.

Quantitative real-time PCR messenger RNA (mRNA) expression of Vimentin, E-cadherin, ZEB2 and Slug was determined using StepOne Real-Time PCR System (Applied Biosystems). $\beta$-actin $(A C T B)$ was used as reference gene. Forward and reverse primers for Vimentin, E-cadherin, ZEB2, Slug and $\beta$-actin gene were designed by PrimerBank (Anne T. Ferguson) (online supplementary table $\mathrm{S} 1$ ). All PCR reactions were carried using Power SYBR Green PCR Master Mix (×2) (Applied Biosystems, Carlsbad, CA, USA). The PCR conditions of each target are mentioned in online supplementary table S1. Each PCR reaction was followed by continuous melt curve analysis. Samples were run in triplicates and to assess contamination, a no template control was included in each PCR run. The relative mRNA expression was calculated using $\Delta \Delta \mathrm{Ct}$ method and fold change values were obtained.

\section{Statistical analysis}

All statistical analyses were performed using SPSS V.18.0 software package for windows (SPSS, Chicago, IL, USA). Categorical variables were compared using $\chi^{2}$ test. Disease-free survival curves were plotted according to the Kaplan-Meier method and analysed by log-rank test. Cox's proportional hazard regression test was used to estimate univariate HRs for prognosis. Nonparametric Spearman rank correlation coefficient was applied to analyse the correlations between mRNA expression of EMT markers. All $\mathrm{p}$ values were two-sided, and those $<0.05$ were considered statistically significant.

\section{RESULTS}

Clinical and pathological features of patients with eyelid SGC A total of 66 cases of eyelid SGC were analysed (table 1). There were 34 men and 32 women with a mean age of $58.1 \pm 13.2$ years (range 30-83 years). In 47 (71\%) cases, tumour was located in the upper eyelid and in $17(26 \%)$ in the lower eyelid. Both lids were involved in two (3\%) cases. The right eye was involved in $37(56 \%)$ and left eye in $29(44 \%)$ patients. Tumours were graded as large $(>20 \mathrm{~mm})$ in $39(59 \%)$ cases. Radiologically, the tumour extended into the orbit in 15 (23\%) cases. The most common primary treatment was frozen section guided wide excision in $56(85 \%)$ tumours followed by eyelid construction. Orbital exenteration was performed in $10(15 \%)$ cases. According to AJCC (seventh edition) staging criteria, 45 $(68 \%)$ cases belonged to early tumour stage IB-II, whereas 21 $(32 \%)$ cases were in stage IIIA, IIIB or IV. In all, $13(20 \%)$ cases presented with locoregional lymph node metastasis at the time of diagnosis.

On histopathological examination, poor differentiation of tumours was observed in 31 (47\%) cases. Pagetoid spread, in which the overlying epidermis is infiltrated by tumour cells, was seen in $20(30 \%)$ cases. Over a mean follow-up period of 34 months (range 4-69 months), local recurrence was seen in 15 $(23 \%)$ cases and death due to systemic metastasis in 4 (6\%) cases. 
Table 1 Patients and tumour characteristics of eyelid sebaceous gland carcinoma cases

\begin{tabular}{|c|c|c|}
\hline \multirow[b]{2}{*}{ Features } & & \multirow{2}{*}{$\begin{array}{l}\text { Total } \\
(n=66 ; \%)\end{array}$} \\
\hline & & \\
\hline \multirow[t]{2}{*}{ Sex } & Male & $34(52 \%)$ \\
\hline & Female & $32(48 \%)$ \\
\hline \multirow[t]{2}{*}{ Age } & $<60$ years & $30(45 \%)$ \\
\hline & $\geq 60$ years & $36(55 \%)$ \\
\hline \multirow[t]{3}{*}{ Location } & Upper lid & $47(71 \%)$ \\
\hline & Lower lid & $17(26 \%)$ \\
\hline & Both upper and lower eyelids & $2(3 \%)$ \\
\hline \multirow[t]{5}{*}{ TNM Stage* } & IB & $11(16 \%)$ \\
\hline & IC & $13(20 \%)$ \\
\hline & ॥ & $21(26 \%)$ \\
\hline & $\| I I A-I I B$ & $17(32 \%)$ \\
\hline & IV & $4(6 \%)$ \\
\hline \multirow[t]{2}{*}{ Surgery } & Excision & $56(85 \%)$ \\
\hline & Exenteration & $10(15 \%)$ \\
\hline Large tumour size & $\geq 2 \mathrm{~cm}$ & $39(59 \%)$ \\
\hline \multirow[t]{2}{*}{ Differentiation } & Poor & $31(47 \%)$ \\
\hline & Well & $69(53 \%)$ \\
\hline Pagetoid spread & Present & $20(30 \%)$ \\
\hline Lymph node metastasis & Present & $13(20 \%)$ \\
\hline Orbital invasion & Present & $15(23 \%)$ \\
\hline Recurrence & Present & $15(23 \%)$ \\
\hline $\begin{array}{l}\text { Tumour-related } \\
\text { death }\end{array}$ & Present & $4(6 \%)$ \\
\hline
\end{tabular}

*American Joint Committee on Cancer (AJCC) Staging, 2009.

\section{Immunoexpression of Vimentin and other EMT markers}

Immunohistochemical staining was performed to analyse the protein expression pattern of EMT markers Vimentin and other target EMT markers E-cadherin, ZEB2 and Slug in tumour cells as well as in normal epidermis of 66 eyelid SGC cases. Cytoplasmic overexpression of Vimentin was seen in tumour cells of $37(56 \%)$ cases. This expression was found to be absent in the adjoining normal epidermis (figure 1 ).

Membranous loss of E-cadherin was observed in tumour lobules of $38(58 \%)$ cases as compared with the normal epidermis and normal sebaceous glands which showed strong membranous positivity for E-cadherin (online supplemental figure S1). Immunohistochemical staining of ZEB2 showed cytoplasmic positivity both in the central and in the peripheral part of tumour lobules in $49(74 \%)$ cases (online supplemental figure S2). Expression of Slug was observed in the nucleus as well as cytoplasm of tumour cells in 18 (27\%) cases (online supplemental figure S3). However, expression of both ZEB2 and Slug was found to be absent in the adjoining normal epidermis.

mRNA expression of Vimentin and other EMT markers in eyelid SGC mRNA expression levels of Vimentin, E-cadherin, ZEB2 and Slug were analysed in a cohort of eyelid SGC samples $(n=42)$ by quantitative PCR (qPCR). High expression levels of Vimentin ( $\geq 2.0$ fold of normal skin RNA) were seen in $16(38 \%)$ cases.

Furthermore, low expression levels of E-cadherin gene $(\geq 2.0$ fold) were found in $27 / 42(64 \%)$ cases. High expression levels of oncogenes ZEB2 ( $\geq 2.0$ fold) and Slug ( $\geq 1.5$ fold) were observed in $30(71 \%)$ and $13(31 \%)$ eyelid SGC cases respectively.

\section{Association between Vimentin mRNA and protein expression}

Of the 42 SGC cases subjected to both mRNA and protein expression of Vimentin, overexpression of Vimentin protein was observed in $24(57 \%)$ cases. On correlating Vimentin mRNA and protein expression, 13 cases showed high expression of both Vimentin mRNA and protein $(\mathrm{p}=0.024)$ (online supplementary table S2).

\section{Association between expression of Vimentin and other EMT markers}

Correlation of Vimentin protein expression with other EMT protein markers demonstrated that Vimentin overexpression was significantly higher in tumours with loss of E-cadherin immunoexpression $(\mathrm{p}<0.001)$. Also, a direct significant association was found between Vimentin and ZEB2 immunoexpression $(\mathrm{p}=0.05)$. However, Slug immunoexpression was not significantly associated with Vimentin immunoexpression $(p=0.276)$ (table 2).

On analysing Spearman's correlation of the expression of Vimentin mRNA with other EMT markers (E-cadherin/ZEB2/ Slug) in 42 SGC samples, Vimentin expression was found to positively correlate with ZEB2 mRNA expression $(p=0.027)$ (table 3). However, E-cadherin $(p=0.574)$ and Slug $(p=0.481)$ mRNA expression did not show any significant association with Vimentin expression (table 3).

\section{Association of Vimentin expression with clinicopathological variables of eyelid SSGC}

Overexpression of Vimentin protein was significantly associated with pagetoid spread $(\mathrm{p}=0.05)$ (table 4). Also, a statistically significant association of Vimentin mRNA expression was seen
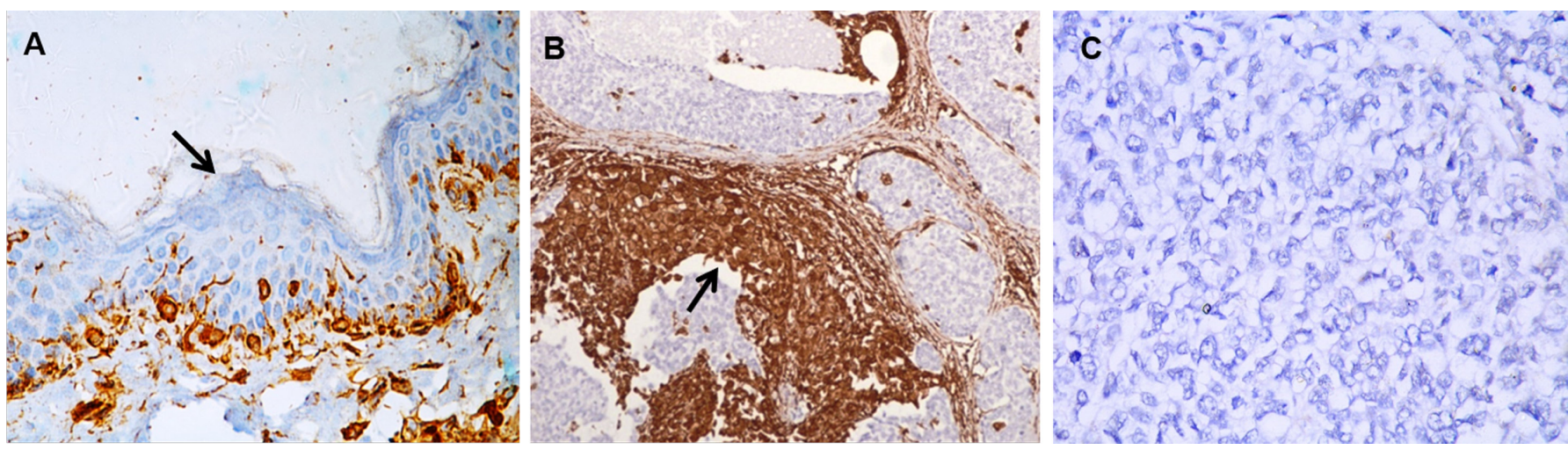

Figure 1 (A) Absence of Vimentin immunoexpression in normal epidermis (arrow). (B) Tumour cells showing strong cytoplasmic positivity of Vimentin in a case of eyelid sebaceous gland carcinoma (arrow). (C) A negative control (original magnification $\mathrm{x} 400$ ). 
Table 2 Association of Vimentin immunostaining with E-cadherin, ZEB2 and Slug immunoexpression

\begin{tabular}{|c|c|c|c|}
\hline \multirow[b]{2}{*}{$\begin{array}{l}\text { Immunohistochemistry } \\
\mathrm{n}(\%)\end{array}$} & \multicolumn{3}{|l|}{$\begin{array}{l}\text { Vimentin } \\
\mathrm{n}(\%)\end{array}$} \\
\hline & $\begin{array}{l}\text { High } \\
37(56 \%)\end{array}$ & $\begin{array}{l}\text { Low } \\
29(44 \%)\end{array}$ & $P$ value \\
\hline E-cadherin high $(28 ; 42 \%)$ & 26 & 2 & $<0.001$ \\
\hline E-cadherin low $(38 ; 58 \%)$ & 11 & 27 & \\
\hline ZEB2 high (49; 74\%) & 31 & 18 & $0.05^{*}$ \\
\hline ZEB2 low $(17 ; 26 \%)$ & 6 & 11 & \\
\hline Slug high (18; 27\%) & 8 & 10 & 0.276 \\
\hline Slug low $(48 ; 73 \%)$ & 29 & 19 & \\
\hline
\end{tabular}

*Significantly associated parameters.

with large tumour size $(\mathrm{p}=0.023)$ and advanced tumour stage $(\mathrm{p}=0.002)($ table 5$)$.

\section{Association of Vimentin expression with clinical outcome}

Vimentin protein $(\mathrm{p}=0.004)$ and mRNA $(\mathrm{p}=0.027)$ expression both showed a significant association with lymph node metastasis. Overexpression of Vimentin protein was observed in 11 of $15(73 \%)$ patients with tumour recurrence and all the four $(100 \%)$ patients who died of systemic metastasis (table 4). The prognostic significance of Vimentin mRNA and protein expression was determined by Kaplan-Meier analysis. Patients with high Vimentin protein expression showed reduced disease-free survival $(p=0.033)$. However, no significant association was found between Vimentin mRNA expression and disease-free survival $(\mathrm{p}=0.489)$ (figure 2$)$.

\section{Univariate analyses of survival}

The univariate Cox regression analyses of clinicopathological features related to patient prognosis were performed in all 66 patients with eyelid SGC. Vimentin protein expression $(p=0.012)$ and advanced tumour stage $(p=0.002)$ both emerged as significant risk factors by univariate analysis (table 6). Orbital invasion also showed a trend towards poor disease-free survival $(p=0.066)$ (table 6).

\section{DISCUSSION}

EMT is an important phenomenon in tumour invasion and metastasis, in which Vimentin acts as a cytoskeletal regulator leading to migration of mesenchymal cells associated with loss of cell adhesion molecule E-cadherin. This is mediated by key transcription factors such as ZEB2, Slug and certain miRNA200 family members. In our earlier study, we have shown that

Table 3 Spearman's rank correlation coefficient and associated $p$ values between the expression of Vimentin, E-cadherin, ZEB2 and Slug in 42 eyelid sebaceous gland carcinoma tumours

\begin{tabular}{llclll}
\hline Target & & E-cadherin & Vimentin & ZEB2 & Slug \\
\hline E-cadherin & Correlation coefficient & 1.000 & 0.089 & -0.001 & 0.134 \\
& Significance level $p$ & - & 0.574 & 0.498 & 0.199 \\
\multirow{2}{*}{ Vimentin } & Correlation coefficient & 0.089 & 1.000 & $0.342\left(^{*}\right)$ & 0.112 \\
& Significance level $p$ & 0.574 & - & 0.027 & 0.481 \\
\multirow{2}{*}{ ZEB2 } & Correlation coefficient & -0.001 & $0.342\left(^{*}\right)$ & 1.000 & $0.344\left(^{*}\right)$ \\
\multirow{2}{*}{ Slug } & Significance level $p$ & 0.498 & 0.027 & - & 0.013 \\
& Correlation coefficient & 0.134 & 0.112 & $0.344\left(^{*}\right)$ & 1.000 \\
\hline & Significance level $p$ & 0.199 & 0.481 & 0.013 & - \\
\hline
\end{tabular}

${ }^{*}$ Significant correlations.
Table 4 Correlation of Vimentin protein expression with clinical and histopathological parameters

\begin{tabular}{|c|c|c|c|c|}
\hline \multirow[b]{2}{*}{ Features } & \multirow[b]{2}{*}{$\begin{array}{l}\text { Total } \\
(n=66)\end{array}$} & \multicolumn{3}{|c|}{ Vimentin immunoexpression } \\
\hline & & $\begin{array}{l}\text { Low } \\
(n=29)\end{array}$ & $\begin{array}{l}\text { High } \\
(n=37)\end{array}$ & $P$ value \\
\hline \multicolumn{5}{|l|}{ Sex } \\
\hline Male & 34 & $14(41 \%)$ & $20(59 \%)$ & \multirow[t]{2}{*}{0.804} \\
\hline Female & 32 & $15(47 \%)$ & $17(53 \%)$ & \\
\hline \multicolumn{5}{|l|}{ Age } \\
\hline$<60$ years & 30 & $16(53 \%)$ & $14(47 \%)$ & \multirow[t]{2}{*}{0.215} \\
\hline$\geq 60$ years & 36 & $13(36 \%)$ & $23(64 \%)$ & \\
\hline \multicolumn{5}{|l|}{ Location } \\
\hline Upper lid & 47 & $21(45 \%)$ & $26(55 \%)$ & \multirow[t]{2}{*}{0.789} \\
\hline Lower lid & 17 & $6(35 \%)$ & $11(65 \%)$ & \\
\hline Both upper and lower lids & 2 & $1(50 \%)$ & $1(50 \%)$ & \\
\hline \multicolumn{5}{|l|}{ TNM Stage* } \\
\hline IB-IC & 24 & $12(50 \%)$ & $12(50 \%)$ & \multirow[t]{3}{*}{0.226} \\
\hline II & 21 & $11(52 \%)$ & $10(48 \%)$ & \\
\hline IIIA-IV & 21 & $6(29 \%)$ & $15(71 \%)$ & \\
\hline \multicolumn{5}{|l|}{ Surgery } \\
\hline Excision & 56 & $25(45 \%)$ & $31(55 \%)$ & \multirow[t]{2}{*}{1.000} \\
\hline Exenteration & 10 & $4(40 \%)$ & $6(60 \%)$ & \\
\hline \multicolumn{5}{|l|}{ Large tumour size } \\
\hline$>2 \mathrm{~cm}$ & 39 & $15(38 \%)$ & $24(62 \%)$ & 0.321 \\
\hline \multicolumn{5}{|l|}{ Differentiation } \\
\hline Poor & 31 & $15(48 \%)$ & $16(52 \%)$ & \multirow[t]{2}{*}{0.62} \\
\hline Well & 35 & $14(40 \%)$ & $21(60 \%)$ & \\
\hline Pagetoid spread & 20 & $5(25 \%)$ & $15(75 \%)$ & $0.05 t$ \\
\hline Lymph node metastasis & 13 & $1(8 \%)$ & $12(92 \%)$ & $0.004 t$ \\
\hline Orbital invasion & 15 & $5(33 \%)$ & $10(67 \%)$ & 0.391 \\
\hline Recurrence & 15 & $4(27 \%)$ & $11(73 \%)$ & 0.149 \\
\hline Tumour-related death & 4 & 0 & $4(100 \%)$ & 0.125 \\
\hline
\end{tabular}

* Significantly associated parameters.

†AJCC Staging, 2009.

aberrant expression of EMT markers ZEB2, E-cadherin and miRNA-200 family members (miRNA-200c/141) correlates with poor prognosis of eyelid SGC. ${ }^{21} 22$ The aim of this study was to determine the expression and prognostic significance of Vimentin in eyelid SGC. Vimentin overexpression has been associated with various malignancies including malignant melanoma, CNS tumours, breast cancer, prostate cancer and gastrointestinal tumours. ${ }^{6}$

In the present study, cytoplasmic overexpression of Vimentin was observed in $56 \%$ of eyelid SGC cases, but it was absent in adjoining normal epithelium. Cytoplasmic localisation of Vimentin has been earlier reported in various cancers including gastric, breast and uterine cervix cancer. ${ }^{23}$ Interestingly, Luo et al have reported nuclear positivity of Vimentin in nasopharyngeal carcinoma. ${ }^{24}$ Other studies on glioblastoma multiforme cell lines $^{25}$ and human neuroblastoma cell lines have also reported nuclear localisation of Vimentin. ${ }^{26}$ However, currently, very little is known about the molecular mechanisms underlying nuclear translocation of Vimentin. Immunohistochemical findings of our study were further validated by qpCR on 42 fresh frozen tissues. mRNA analysis is useful to identify the molecular mechanisms involved in dysregulation of EMT pathway in tumours. Increased Vimentin mRNA expression was found in 38\% cases. The high concordance between Vimentin gene and protein expression further validates the importance of Vimentin as an EMT marker in SGC. Similar results of high Vimentin protein 
Table 5 Correlation of Vimentin mRNA expression with clinical and histopathological parameters

\begin{tabular}{|c|c|c|c|c|}
\hline \multirow[b]{2}{*}{ Features } & \multirow[b]{2}{*}{$\begin{array}{l}\text { Total } \\
(\mathrm{n}=42)\end{array}$} & \multicolumn{3}{|c|}{ Vimentin mRNA expression } \\
\hline & & $\begin{array}{l}\text { Low } \\
(n=26)\end{array}$ & $\begin{array}{l}\text { High } \\
(n=16)\end{array}$ & $P$ value \\
\hline \multicolumn{5}{|l|}{ Sex } \\
\hline Male & 20 & $10(50 \%)$ & $10(50 \%)$ & 0.204 \\
\hline Female & 22 & $16(73 \%)$ & $6(27 \%)$ & \\
\hline \multicolumn{5}{|l|}{ Age } \\
\hline$<60$ years & 20 & $15(75 \%)$ & $5(25 \%)$ & 0.121 \\
\hline$\geq 60$ years & 22 & $11(50 \%)$ & $11(50 \%)$ & \\
\hline \multicolumn{5}{|l|}{ Location } \\
\hline Upper lid & 31 & $20(65 \%)$ & $11(35 \%)$ & 0.304 \\
\hline Lower lid & 11 & $6(55 \%)$ & $5(45 \%)$ & \\
\hline \multicolumn{5}{|l|}{ TNM Stage* } \\
\hline IB-IC & 16 & $15(94 \%)$ & $1(6 \%)$ & $0.002 t$ \\
\hline II & 11 & $5(45 \%)$ & $6(55 \%)$ & \\
\hline IIIA-IV & 15 & $6(40 \%)$ & $9(60 \%)$ & \\
\hline \multicolumn{5}{|l|}{ Surgery } \\
\hline Excision & 36 & $22(61 \%)$ & $14(39 \%)$ & 1.000 \\
\hline Exenteration & 6 & $4(67 \%)$ & $2(33 \%)$ & \\
\hline \multicolumn{5}{|l|}{ Large tumour size } \\
\hline$>2 \mathrm{~cm}$ & 24 & $11(46 \%)$ & $13(54 \%)$ & $0.02 t$ \\
\hline \multicolumn{5}{|l|}{ Differentiation } \\
\hline Poor & 18 & $12(67 \%)$ & $6(33 \%)$ & 0.75 \\
\hline Well & 24 & $14(58 \%)$ & $10(42 \%)$ & \\
\hline Pagetoid spread & 14 & $8(57 \%)$ & $6(43 \%)$ & 0.742 \\
\hline Lymph node metastasis & 10 & $3(30 \%)$ & $7(70 \%)$ & $0.027 \dagger$ \\
\hline Orbital invasion & 10 & $5(50 \%)$ & $5(50 \%)$ & 0.465 \\
\hline Recurrence & 13 & $8(62 \%)$ & $5(38 \%)$ & 1.000 \\
\hline Tumour-related death & 1 & 0 & $1(100 \%)$ & 0.381 \\
\hline
\end{tabular}

${ }^{*}$ AJCC Staging, 2009.

tSignificantly associated parameters.

mRNA, messenger RNA.
Table 6 Univariate analysis of risk factors affecting disease-free survival in patients with eyelid sebaceous gland carcinoma (COX proportional-hazard regression model)

\begin{tabular}{lll}
\hline \multirow{2}{*}{ Variables } & \multicolumn{2}{l}{ Univariate analysis } \\
\cline { 2 - 3 } & P value & Relative risk $(95 \% \mathrm{CI})$ \\
\hline Tumour size $>20 \mathrm{~mm}$ & 0.106 & $2.14(0.85$ to 5.34$)$ \\
\hline Advanced tumour stage & $0.002^{*}$ & $3.58(1.61$ to 7.97$)$ \\
\hline Orbital invasion & $0.08 \dagger$ & $2.15(0.95$ to 4.87$)$ \\
\hline Pagetoid spread & 0.238 & $0.59(0.25$ to 1.41$)$ \\
\hline Poor tumour differentiation & 0.597 & $1.23(0.57$ to 2.7$)$ \\
\hline Orbital exenteration & 0.179 & $1.88(0.75$ to 4.72$)$ \\
Vimentin expression & $0.027^{*}$ & $2.76(1.04$ to 7.34$)$ \\
\hline
\end{tabular}

*Significant $p$ value.

†Borderline Significance.

and gene expression have been reported in gastric cancer $^{27}$ and colorectal cancer. ${ }^{28}$

Vimentin overexpression correlated with clinicopathological high-risk features of SGC including advanced tumour stage $(\mathrm{p}=0.002)$, large tumour size $(\mathrm{p}=0.023)$ and pagetoid spread $(p=0.05)$. Correlation of Vimentin expression with advanced clinical stage was also observed in nasopharyngeal ${ }^{24}$ and colorectal cancer. ${ }^{29}$ Analogous findings for association of Vimentin expression with higher $\mathrm{T}$ group have been reported for non-small-cell lung cancer, ${ }^{16}$ colorectal cancer ${ }^{28}$ and pancreatic ductal adenocarcinoma. ${ }^{30}$

Univariate survival analysis of patient with eyelid SGC cohort showed that high Vimentin immunoexpression was an indicator of adverse outcome. Vimentin also emerged as a predictor of lymph node metastasis, indicating that EMT was present in aggressive SGC cases. Various studies on malignancies such as nasopharyngeal carcinoma, ${ }^{24}$ colorectal cancer, ${ }^{28}$ head and neck squamous cell carcinoma ${ }^{31}$ and oral squamous cell carcinoma ${ }^{32}$ have demonstrated Vimentin overexpression as predictor of lymph node metastasis and poor prognosis.

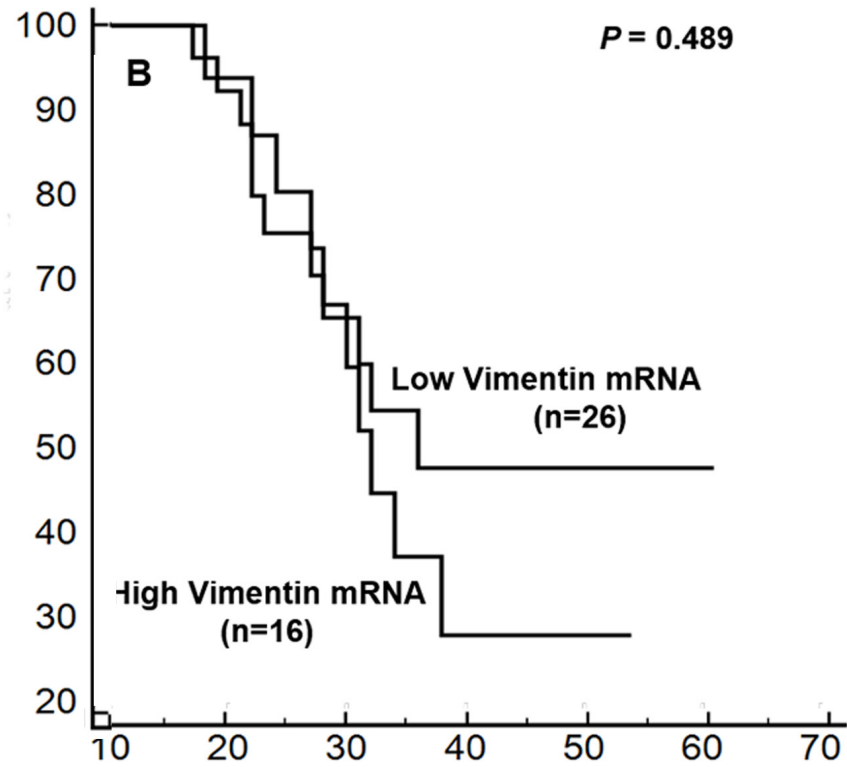

Figure 2 Kaplan-Meier survival curves showing disease-free survival rates in patients with eyelid sebaceous gland carcinoma according to the status of Vimentin protein and mRNA expression. (A) Patients with high Vimentin protein expression showed worse prognosis than those with low Vimentin protein expression $(p=0.033)$. (B) Patients with high Vimentin mRNA expression did not show any significant association with poor diseasefree survival $(p=0.489)$. mRNA, messenger RNA. Titles and legends to supplementary figures. 
There was an inverse correlation between Vimentin and E-cadherin immunoexpression in this study. Vimentin induces a mesenchymal phenotype associated with reduced E-cadherin levels in gastric cancer, ${ }^{27}$ oral squamous cell carcinoma ${ }^{33}$ and hepatocellular carcinoma. ${ }^{34}$ The expression of EMT associated transcription factor ZEB2 showed a direct significant association with Vimentin at both mRNA and protein level, further validating that Vimentin contribute towards EMT in eyelid SGC. Similar findings of association between Vimentin and ZEB2 expression are reported in renal cell carcinoma, ${ }^{14}$ and invasive epithelial breast cancer cell lines MDA-231, BT549 and Hs578T. ${ }^{35}$ Overexpression of Slug was observed in only few SGC cases and it did not correlate with Vimentin expression.

To the best of our knowledge, overexpression of Vimentin and its contribution towards EMT in eyelid SGC have been demonstrated for the first time. Its overexpression was related to tumour metastasis and poor survival of patients with SGC and hence can be recommended as a predictor of poor outcome.

Contributors SS, KC, AS: Conception and design. MB: Analysis, interpretation and manuscript preparation. SK, NP, MSB, SB: Acquisition of clinical data.

Funding Funding support for the study was provided by All India Institute of Medical Sciences (grant no.: F.8-262/A-262/2014/RS) and Indian Council of Medical Research (grant 3/2/2/240/2014-NCD-III).

\section{Competing interests None declared.}

Patient consent for publication Obtained.

Ethics approval The study was conducted after approval from Institute Ethics Committee, AlIMS, New Delhi (Ref. No. IEC/NP-250/03.07.2014) and informed consent was obtained from all patients participating in this study. The study was carried out in accordance with the tenets of the Declaration of Helsinki principles.

Provenance and peer review Not commissioned; externally peer reviewed.

ORCID iDs

Seema Sen http://orcid.org/0000-0001-9649-9616

Neelam Pushker http://orcid.org/0000-0001-7872-1172

\section{REFERENCES}

1 Lee SB, Saw SM, Au Eong KG, et al. Incidence of eyelid cancers in Singapore from 1968 to 1995. Br J Ophthalmol 1999;83:595-7.

2 Kale SM, Patil SB, Khare N, et al. Clinicopathological analysis of eyelid malignancies A review of 85 cases. Indian J Plast Surg 2012;45:22-8.

3 Cook BE, Bartley GB. Epidemiologic characteristics and clinical course of patients with malignant eyelid tumors in an incidence cohort in Olmsted County, Minnesota. Ophthalmology 1999;106:746-50

4 Kass LG, Hornblass A. Sebaceous carcinoma of the ocular adnexa. Surv Ophthalmol 1989;33:477-90.

5 Kalluri R, Weinberg RA. The basics of epithelial-mesenchymal transition. J Clin Invest 2009;119:1420-8

6 Satelli A, Li S. Vimentin in cancer and its potential as a molecular target for cancer therapy. Cell Mol Life Sci 2011;68:3033-46.

7 Comijn J, Berx G, Vermassen P, et al. The two-handed E box binding zinc finger protein SIP1 downregulates E-cadherin and induces invasion. Mol Cell 2001;7:1267-78.

8 Elloul S, Elstrand MB, Nesland JM, et al. Snail, slug, and Smad-interacting protein 1 as novel parameters of disease aggressiveness in metastatic ovarian and breast carcinoma. Cancer 2005;103:1631-43.

9 Shioiri M, Shida T, Koda K, et al. Slug expression is an independent prognostic parameter for poor survival in colorectal carcinoma patients. Br J Cancer 2006:94:1816-22.
10 Uchikado Y, Natsugoe S, Okumura $\mathrm{H}$, et al. Slug expression in the E-cadherin preserved tumors is related to prognosis in patients with esophageal squamous cel carcinoma. Clin Cancer Res 2005;11:1174-80.

11 Uchikado Y, Okumura H, Ishigami S, et al. Increased slug and decreased E-cadherin expression is related to poor prognosis in patients with gastric cancer. Gastric Cancer 2011:14:41-9.

12 Miura N, Yano T, Shoji F, et al. Clinicopathological significance of Sip1-associated epithelial mesenchymal transition in non-small cell lung cancer progression. Anticancer Res 2009;29:4099-106.

13 Kurahara H, Takao S, Maemura K, et al. Epithelial-mesenchymal transition and mesenchymal-epithelial transition via regulation of ZEB-1 and ZEB-2 expression in pancreatic cancer. J Surg Oncol 2012;105:655-61.

14 Fang Y, Wei J, Cao J, et al. Protein expression of ZEB2 in renal cell carcinoma and its prognostic significance in patient survival. PLoS One 2013;8:e62558.

15 Ainbinder DJ, Esmaeli B, Groo SC, et al. Introduction of the 7th edition eyelid carcinoma classification system from the American Joint Committee on CancerInternational Union Against Cancer staging manual. Arch Pathol Lab Med 2009;133:1256-61.

16 Tsoukalas N, Aravantinou-Fatorou E, Tolia M, et al. Epithelial-mesenchymal transition in non small-cell lung cancer. Anticancer Res 2017;37:1773-8.

17 Singhai R, Patil V, Jaiswal S, et al. E-cadherin as a diagnostic biomarker in breast cancer. N Am J Med Sci 2011;3:227-33.

18 Qi S, Song Y, Peng Y, et al. ZEB2 mediates multiple pathways regulating cell proliferation, migration, invasion, and apoptosis in glioma. PLoS One 2012;7:e38842.

19 Nagaishi M, Nobusawa S, Tanaka Y, et al. Slug, Twist, and E-cadherin as immunohistochemical biomarkers in meningeal tumors. PLoS One 2012;7:e46053.

20 Tanishima H, Gui T, Sun Y, et al. Snail protein expression as a hallmark of gastric carcinoma in biopsy samples. International Scholarly Research Notices 2012;132472.

21 Bhardwaj M, Sen S, Sharma A, et al. ZEB2/SIP1 as novel prognostic indicator in eyelid sebaceous gland carcinoma. Hum Pathol 2015:46:1437-42.

22 Bhardwaj M, Sen S, Chosdol K, et al. miRNA-200c and miRNA-141 as potential prognostic biomarkers and regulators of epithelial-mesenchymal transition in eyelid sebaceous gland carcinoma. Br J Ophthalmol 2017;101:536-42.

23 Iwatsuki M, Mimori K, Fukagawa T, et al. The clinical significance of vimentinexpressing gastric cancer cells in bone marrow. Ann Surg Oncol 2010;17:2526-33.

24 Luo W, Fang W, Li S, et al. Aberrant expression of nuclear vimentin and related epithelial-mesenchymal transition markers in nasopharyngeal carcinoma. Int J Cancer 2012;131:1863-73

25 Wang L, Zhang J, Banerjee S, et al. Sumoylation of vimentin354 is associated with PIAS3 inhibition of glioma cell migration. Oncotarget 2010;1:620-7.

26 Mergui X, Puiffe M-L, Valteau-Couanet D, et al. P21WAF1 expression is regulated by nuclear intermediate filament vimentin in neuroblastoma. BMC Cancer 2010;10.

27 Otsuki S, Inokuchi M, Enjoji M, et al. Vimentin expression is associated with decreased survival in gastric cancer. Oncol Rep 2011:25:1235-42.

28 Toiyama Y, Yasuda H, Saigusa S, et al. Increased expression of slug and vimentin as novel predictive biomarkers for lymph node metastasis and poor prognosis in colorectal cancer. Carcinogenesis 2013;34:2548-57.

29 Liu L-G, Yan X-B, Xie R-T, et al. Stromal expression of vimentin predicts the clinical outcome of stage II colorectal cancer for high-risk patients. Med Sci Monit 2017:23:2897-905.

30 Handra-Luca A, Hong S-M, Walter K, et al. Tumour epithelial vimentin expression and outcome of pancreatic ductal adenocarcinomas. Br J Cancer 2011:104:1296-302.

31 Nijkamp MM, Span PN, Hoogsteen IJ, et al. Expression of E-cadherin and vimentin correlates with metastasis formation in head and neck squamous cell carcinoma patients. Radiother Oncol 2011:99:344-8.

32 Liu S, Liu L, Ye W, et al. High vimentin expression associated with lymph node metastasis and predicated a poor prognosis in oral squamous cell carcinoma. Sci Rep 2016;6.

33 Liu L-K, Jiang $X-Y$, Zhou $X-X$, et al. Upregulation of vimentin and aberrant expression of $E$-cadherin/beta-catenin complex in oral squamous cell carcinomas: correlation with the clinicopathological features and patient outcome. Mod Pathol 2010;23:213-24.

34 Zhai X, Zhu H, Wang W, et al. Abnormal expression of EMT-related proteins, S100A4, vimentin and E-cadherin, is correlated with clinicopathological features and prognosis in HCC. Med Oncol 2014;31.

35 Bindels S, Mestdagt M, Vandewalle $C$, et al. Regulation of vimentin by SIP1 in human epithelial breast tumor cells. Oncogene 2006;25:4975-85. 